\title{
Staged Abdominal Repair Surgery in Abdominal Compartment Syndrome- An Observational Study
}

\author{
Satyajeet Kr Singh, Chitrangada, Nitin kr Singh. Prof Subrata Nag
}

\begin{abstract}
:
Objective:Staged Abdominal Repair Surgery in Abdominal Compartment Surgery.Research design and methods: The study was conducted on 45 patients who underwent laparotomy due to acute abdominal conditions and abdomen was closed in staged manner using staged abdominal repair surgery also known as STAR operation. Statistical analysis was performed and results analysed.Results: The present series comprising of 45 cases had low rate of grave complications like entero-cutaneous fistulae formation (< 16\%), intraabdominal infection (approx 17\%), development of bedsore (approx 13\%), chest infection (approx 22\%). Average hospital stay was of 3 weeks and postoperative mortality of approximately $11 \%$.Conclusions: We thus conclude that the STAR technique has definite edge over previous techniques of temporary abdominal closure and shows a new path of abdominal closure to the surgical fraternity .
\end{abstract}

The effects of increased abdominal pressure on various organ systems has been noted over the past century. Intra-abdominal hypertension (IAH) and abdominal compartment syndrome (ACS) have been identified as a cause of organ dysfunction and mortality in several subsets of critically ill patients. The staged abdominal repair operation popularly known as STAR operation is a technique of temporary closue of abdomen during primary surgery followed by a second surgery 24 to 48 hours later ending in final aponeurosis to aponeurosis closure of abdomen.. In abdominal compartment syndrome; this operation, is gaining popularity because it is life saving in critically ill patients and has lower complication rate as well.

Intra-abdominal pressure (IAP) is the steady pressure within the abdominal cavity.For critically ill patients, an IAP of 5 to $7 \mathrm{~mm}$ of $\mathrm{Hg}$ is considered normal. Intra-abdominal pressure (IAP) is graded as follows :

\begin{tabular}{|l|l|}
\hline Grade I - IAP & 2 to $15 \mathrm{~mm}$ of $\mathrm{Hg}$ \\
\hline Grade II - IAP & 16 to $20 \mathrm{~mm}$ of $\mathrm{Hg}$ \\
\hline & 21 to $25 \mathrm{~mm}$ of $\mathrm{Hg}$ \\
Grade III - IAP & \\
\hline Grade IV - IAP & $\square-25 \mathrm{~mm} \mathrm{of} \mathrm{Hg}$ \\
\hline
\end{tabular}

Abdominal perfusion pressure (APP) is calculated as the mean arterial pressure (MAP) minus the IAP i.e $\mathrm{APP}=$ MAP - IAP. Multiple regression analysis have found that APP is better than other resuscitation endpoints such as arterial $\mathrm{pH}$, base deficits, arterial lactate, and hourly urinary output for predicting outcomes.A target APP of at least $60 \mathrm{mmHg}$ is correlated with improved survival from IAH and ACS.

Intra-abdominal hypertension (IAH) is defined as a sustained intra-abdominal pressure $>12 \mathrm{~mm}$ of $\mathrm{Hg}$. IAH impairs the function of nearly every organ-system. IAH decreases cardiac output by impairing cardiac function and reducing venous return. It causes cephalad movement of the diaphragm which leads to reduced ventricular compliance and reduced contractility. IAH obstructs blood flow in the inferior vena cava leading to diminished venous flow from the lower extremities resulting in formation of peripheral edema and increase risk of deep vein thrombosis.It causes alveolar barotrauma in mechanically ventilated patients. It reduces chest wall compliancewhich further lead to arterial hypoxemia, hypercarbia and pulmonary infections. It leads to impairment of renal function by causing renal artery vasoconstriction and renal vein compression. Gut is very sensitive to rise in intra abdominal pressure. IAH compresses thin-walled mesenteric veins which impairs venous flow from the intestine and causes intestinal edema. The intestinal swelling further increases intraabdominal pressure, initiating a vicious cycle.The end result is worsened hypoperfusion, bowel ischemia, decreased intramucosal $\mathrm{pH}$, and lactic acidosis.

Abdominal compartment syndrome defined as a sustained intra-abdominal pressure $>20 \mathrm{~mm} \mathrm{Hg}$ with or without abdominal perfusion pressure [APP] of $<60 \mathrm{~mm} \mathrm{Hg}$ that is associated with new organ dysfunction.For clinical purposes, ACS is better defined as IAH-induced new organ dysfunction, without strict intra-abdominal pressure threshold..Patients with intra-abdominal pressure below $10 \mathrm{~mm} \mathrm{Hg}$ generally do not have ACS. ACS can be primary due to injury or disease in abdomino pelvic organs, secondary due to conditions not originating from abdomen or pelvis such as fluid resuscitation, sepsis or burns. Recurrent ACS refers to conditions in which ACS develops following previous medical or surgical conditions. ACS generally occurs in 
patients who are critically ill due to various medical and surgical conditions such as trauma, burns, liver transplantation, sepsis , ascitis , bowel distension abdominal surgery etc.

\section{Methods:}

A study was conducted in 45 patients who underwent laparotomy due to acute abdominal conditions and abdomen was closed in staged manner using staged abdominal repair surgery. The study was performed in accordance with the ethical principles and was approved by the institutional ethics review board. Each participant provided a written informed consent.

The inclusion criteria included patients who had:

- $\quad$ Pre-operative IAP of $20 \mathrm{~mm}$ of $\mathrm{Hg}$ or above measured by U-tube method.

- Excessive intraperitoneal edema preventing abdominal closure without undue tension.

- Gut above the level of wound when looked horizontally before closure

Patients less than 10yrs of age with acute abdominal conditions were excluded from the study

Intra-abdominal pressure (IAP) was measured bed side by using U-tube technique. Patient was positioned supine with the head on the bed flat with a urinary catheter in place. When the patient is quiet and calm and and abdominal contractions absent urinary catheter was raised above the patient, allowing an $U$ shaped loop to develop. Connection site (the zero level) where the catheter meets the drainage tubing in line with symphysis pubis was leveled. Fluid column was allowed to settle and using the centimeter ruler, measurement was done from 'zero' connection site to meniscus of the fluid column

Staged abdominal repair surgery was planned either preoperatively or during the operation if pathology so demanded. After dealing with pathology of abdomen and giving two mallecot drains one in right flank and one in pelvis, abdomen was left open with cotton drape sutured to skin margin to prevent evisceration of intestine. Patients were shifted to ward with dressings over it.After 24 hours patients were again brought to OT, drape removed, and corrugated rubber drain was stitched to skin margin under ketamine anaesthesia. Rectus sheath was left untouched. Patients were again shifted to ward .On the $8^{\text {th }}$ day, under ketamine anaesthesia, the corrugated rubber that was removed and aponeurosis to aponeurosis closure was done.

Post operatively vitals were monitored. $\mathrm{Hb} \%$, total and different count of WBC, kidney function test, serum electrolytes such as $\mathrm{Na}^{+}, \mathrm{K}^{+}, \mathrm{Ca}^{+}$and bicarbonate were repeated on alternate days. Dressing of wound was done daily. IAP was measured 6 hourly for the first 3 days and then 12-hourly.

\section{Results And Analysis:}

The study was conducted on 45 cases of acute abdomen who underwent staged abdominal repair surgery . the age was distribution was as follows:

\begin{tabular}{|c|c|c|}
\hline Age Group in years & No. of Cases & Percentage \\
\hline $0-10$ & 0 & $0 \%$ \\
\hline $11-20$ & 5 & $11.11 \%$ \\
\hline $21-30$ & 10 & $22.22 \%$ \\
\hline $31-40$ & 10 & $22.22 \%$ \\
\hline $41-50$ & 12 & $26.66 \%$ \\
\hline$>50$ years & 08 & $17.77 \%$ \\
\hline
\end{tabular}

\section{TABLE 1 : Age distribution of patients}

Out of 45 patients studied in present series maximum incidence of patients undergoing STAR operation was between 41-50 years (26.66\%); followed by age group 21-30 years (22.22\%). 40.43\% of patients undergoing STAR operation were more than 40 years of age.

Out of 45 patients, $15(33.34 \%)$ had duodenal perforation, $10(22.22 \%)$ had gastric perforation; 08 $(17.17 \%)$ had ileal perforation; $05(11.11 \%)$ had intestinal obstruction due to band and adhesions; $03(6.66 \%)$ had appendicular perforation; $03(6.66 \%)$ had intestinal obstruction due to volvulus; and $1(2.22 \%)$ had traumatic jejunal perforation.

\begin{tabular}{|l|c|c|}
\hline \multicolumn{1}{|c|}{ Pathology } & No. of Cases (Total no-45) & Percentage \\
\hline Duodenal perforation & 15 & $33.34 \%$ \\
\hline Gastric perforation & 10 & $22.22 \%$ \\
\hline Ileal perforation & 08 & $17.17 \%$ \\
\hline Appendicular perforation & 03 & $6.66 \%$ \\
\hline Intestinal obstruction due to band and adhesions & 05 & $11.11 \%$ \\
\hline Intestinal obstruction due to volvulus & 03 & $6.66 \%$ \\
\hline Traumatic jejunal perforation & 01 & \\
\hline
\end{tabular}

TABLE 2 : Different pathology of acute abdominal conditions for which STAR operation was performed. 
At the time of admission out of 45 patients 25 (55.55\%) had IAP in the range of 21-30 mm of $\mathrm{Hg} ; 10$ (22.23\%) had IAP more than $30 \mathrm{~mm} \mathrm{Hg} ; 8(8.88 \%)$ had the IAP in range 11-20 $\mathrm{mm}$ of $\mathrm{Hg}$; 2 (4.44\%) had IAP less than $10 \mathrm{~mm}$ of $\mathrm{Hg}$.

IAP was more than $20 \mathrm{~mm}$ of $\mathrm{Hg}$ in 35 patients $(77.78 \%)$ and was due to intra-abdominal peritonitis, intra-peritoneal swelling of viscera and continuous fluid administration and distension of abdomen. After 24 hours of STAR operation $30(66.66 \%)$ had IAP of less than $10 \mathrm{~mm}$ of $\mathrm{Hg}, 13(28.88 \%)$ had IAP in the range of 11-20 $\mathrm{mm}$ of $\mathrm{Hg}, 2$ (4.45\%) had IAP in the range of 21-30 $\mathrm{mm}$ of $\mathrm{Hg}$ and none of the patient had IAP of more than $30 \mathrm{~mm}$ of $\mathrm{Hg}$. IAP was less than $20 \mathrm{~mm}$ of $\mathrm{Hg}$ in 43 patients $(95.55 \%)$ at 24 hours of STAR operation was due to the decompression of abdomen by laparotomy and staged abdominal closure of abdomen . After 48 hours; $36(80 \%)$ had IAP in the range of $0-10 \mathrm{~mm}$ of $\mathrm{Hg} ; 8(17.77 \%)$ had IAP in the range of $11-20 \mathrm{~mm} \mathrm{of} \mathrm{Hg}$; $1(2.23 \%)$ had IAP in the range of 21-30 $\mathrm{mm}$ of $\mathrm{Hg}$. None of the patient had IAP of more than $30 \mathrm{~mm}$ of $\mathrm{Hg}$.IAP was less than $20 \mathrm{~mm}$ of $\mathrm{Hg}$ in 44 patients at 48 hours of STAR operation. It was due to the serial closure of abdomen exerting no tension at the wound edge.

at the $6^{\text {th }}$ post-operative day, $40(88.88 \%)$ had IAP in the range of $0-10 \mathrm{~mm}$ of $\mathrm{Hg}, 5(11.12 \%)$ had IAP in the range of 11-20 $\mathrm{mm}$ of $\mathrm{Hg}$. None of the patients had IAP of more than $20 \mathrm{~mm} \mathrm{of} \mathrm{Hg}$.

Thus, out of 45 patients, who underwent STAR operation, all patients (100\%) had IAP below $20 \mathrm{~mm}$ of $\mathrm{Hg}$ at $6^{\text {th }} \mathrm{POD}$, and they were not having abdominal compartment syndrome (ACS) according to the definition of ACS.

\begin{tabular}{|c|c|c|c|c|}
\hline $\begin{array}{l}\text { Intra-abdominal pressure } \\
\text { (IAP) } \begin{array}{c}\text { Number of cases (Total no=45) } \\
\text { method U-tube }\end{array}\end{array}$ & \multicolumn{3}{|l|}{} \\
& $\begin{array}{l}\text { Preoperative } \\
\text { period }\end{array}$ & $\mathbf{1}^{\text {st }}$ postoperative day & $\mathbf{2}^{\text {nd }}$ postoperative day & $\begin{array}{c}\mathbf{6}^{\text {th }} \text { postoperative } \\
\text { day }\end{array}$ \\
\hline $0-10 \mathrm{~mm}$ of Hg & 2 & & & 40 \\
\hline $11-20 \mathrm{~mm}$ of Hg & 8 & 30 & 36 & 05 \\
\hline $21-30 \mathrm{~mm}$ of Hg & 25 & 13 & 08 & 00 \\
\hline$>30 \mathrm{~mm}$ of Hg & 10 & 02 & 01 & 00 \\
\hline
\end{tabular}

TABLE 3 : Intra-abdominal pressure (IAP) measured by U-tube method in preoperative \& postoperative period.

The incidence of post operative complications was low. Complications included entero-cutaneous fistula formation, intra-abdominal infection, bed sores and chest infection. Out of 45 patients, 36 patients $(80.00 \%)$ had hospital stay between 11-20 days. In 9 patients (20\%), total hospital stay was more than 20 days.

\begin{tabular}{|c|c|c|}
\hline Complications & No. of Cases & Percentage \\
\hline Entero-cutaneous fistula formation & 07 & $15.55 \%$ \\
\hline Intraabdominal infections & 08 & $17.17 \%$ \\
\hline Bedsores & 06 & $13.33 \%$ \\
\hline Chest infections & 10 & $22.22 \%$ \\
\hline Mortality & 05 & $11.11 \%$ \\
\hline
\end{tabular}

TABLE 4 : Incidence of postoperative complications

\section{Discussion:}

Abdominal compartment syndrome is defined as the sudden increase in intra-abdominal pressure resulting in the alteration in respiratory mechanism, hemodynamic parameters, renal as well as cerebral perfusion. Any insult that results in acute increase in the volume of abdominal components sufficient to cause pressure related end organ dysfunction can lead to abdominal compartment syndrome. These can include abdominal trauma, ruptured abominal artey aneurysm, retro peritoneal haemorrhage, pancreatitis, burns and sepsis. Open abomen has become a significantly more common intermediate step in treatment of abdominal emergencies. The main goal after the open abdomen procedure is to stabilize the patient's condition and achieve abdominal closure as soon as possible. There are many methods of temporary closure of abdomen. These include the Wittman patch, the abdominalreapproximation anchor system, staged abdominal repair, negative pressure wound therapy and mesh mediated traction technique.

Staged abdominal repair surgery (STAR) operation is a technique of serial operation, planned either before or during the first index operation.During the course of treatment a controlled tension is exerted on the margins avoiding an artificially caused "abdominal compartment syndrome" due to intra-abdominal inflammation, oedema and paralytic ileus. 
STAR operation is gaining popularity because it has low complication rate and is easy to perform. Virtually all materials which are non-reactive to body tissues, can be used for temporary closure of abdomen such as corrugated rubber drain sheet and cotton towels .

Being a new technique, the STAR operation requires further evaluation. The available surgical literature speaks little.

According to Wittmann and colleagues, STAR operation appears to reduce mortality by $50 \%$ over the standard operations.

STAR operation, facilitate easy second look after stabilization of the patient's general condition, decompresses the abdomen and helps in organ recompensation.

\section{Summary And Conclusion}

The present study, popularly known as "STAR operation in abdominal compartment syndrome" is becoming day by day popular because of time and life saving characteristics with lower complication rate in critically ill patients suffering from acute abdomen. The present series comprising 45 cases had very low rate of grave complications like entero-cutaneous fistulae formation ( $<16 \%)$, intra-abdominal infection (approx. 17\%), development of bedsore (approx. 13\%), chest infection (approx. 22\%). An average hospital stay of 3 weeks and postoperative mortality of only $11 \%$ (approx).

In the present series, probably it shows a new path of abdominal closure to the surgical fraternity and requires more and more studies at highly developed surgical centres to establish the procedure.So, we conclude that the STAR technique has definite edge over previous techniques involving zipper application, retention sutures and various other techniques of temporary abdominal closure like VAC, vaccum pack, artificial burr (Wittmann Patch), bagota bag, mesh application and loose packing.

\section{Bibliography:}

[1] Bailey and Love's short practice of surgery, $24^{\text {th }}, 25^{\text {th }}$ and $26^{\text {th }}$ edition.

[2] Bloomfield GL, Blocker CR, Fakhry IF, Sica DA, Sururman HJ, Elevated intra-abdominal pressure increases plasma renin activity and aldosterome level. J Trauma : 1997: 42: 997-1004.

[3] Bloomfield GL, Ridings PC, Blocher CR, Marmnrocu A, Sugarman HJ. A proposed relationship between increased intra-abdominal intrathoracic and intracranial pressure. Crit Care Med, 1997;25 : 496-503.

[4] Burch JM, Moore EE, Moore FA. The abdominal compartment syndrome. Surg Clin North Am. 1996 : 76 : $833-42$

[5] Clinical anatomy by regions, Rechard S. Snell, $8^{\text {th }}$ edition.

[6] Concise textbook of surgery, $5^{\text {th }}$ edition.

[7] Critical care nurse : Vol. 32, No. 1 Febuary 2012, Page No. 28 - U-tube method of measuring Intra-abdominal pressure.

[8] Cullen DJ, Coyle JP, Teplick R, Long MC. Cardiovascular pulmonary and renal effects of massively increased intra-abdominal pressure in critically ill patients crit care Med. 1989; 17: 118-21.

[9] De Lact I, Malbrain ML, Jadoul JL, Rogiers P, Surgeon. Renal implications of increased IAP. Acta clin Belg Suppl. 2007; 62; 11930.

[10] De Lact, Hoste E, Verholen E, De Waele JJ. The effect of neuromuscular blockers in patients with intra-abdominal hypertension. Intensive Care Med. 2007; 33 (10) : 1811-14.

[11] De lact, Malbrain ML, ICU management of the patients with intra-abdominal hypertension : What to do, when and to whom ? Acta clin Belg Suppl 2007; 62-190-9.

[12] De waele JJ, Hoste EA, Malbrain ML, Deconpressive laparotomy for abdominal compartment syndrome - a critical analysis. Crit Care 2006 : 10: R51.

[13] De Waele, De Laet I, Malbrain ML. Rational Intra-abdominal pressure monitoring : how to do it ? Acta clin Belg Suppl. 2007; 62 : $16-25$.

[14] Doughorty FL, Honggn L, Taichman D, Hansen-Flaschen J, Fuchs BD. Abdominal compartment syndrome is common in Medical ICU patients receiving large-volume I.V. fluid. J. Intensive care med 2007; $22: 294-9$.

[15] Durairaj L, Schmidta GA. Fluid therapy in resuscitation sepsis. Chest, 2008; 133; 252-63.

[16] Farquharson's textbook of operative general surgery, $9^{\text {th }}$ edition.

[17] Ivatury RR, Sugermon HJ, Peitzman AB. Abdominal compartment syndrome : 20 cognition and management. Adv Surg. 2001 : 35 : 251-69.

[18] Keith and Moore, Clinical Anatomy.

[19] Kirk Patrick AW, De Waele JJ, Ball CH, Ranson K, Widders, Laupland KB. The secondary and recurrent abdominal compartment syndrome. Acta Clin Belg Suppl. 2007; 62:60-5.

[20] Lact I, Melbrai Ml, Current insiguts in intra-abdominal hypertension and abdominal compartment syndrome. Med. Intensiva, 2007: 31-88-89.

[21] Lonsoff JE, Richman BW, Jones JW, Temporary coverage, and reclosure of the abdomen, Frequently asked questions. J Am Coll Surg 2002; $195: 105-15$

[22] Maingot's abdominal operations, $11^{\text {th }}$ edition and $12^{\text {th }}$ edition.

[23] Malbrain ML, Cheatham ML, Kirkpatrick A, Surgue M, Dewale J, Ivaturg R. Abdominal compartment syndrome : It's time to pay attention ! Intensive Care Med. 2006; $32: 1912-14$

[24] Malbrain ML, Cheathan ML, Kirpatrick A, Surgure M, Parr M. De Waele J, et al. Results from the International conference of experts of intra-abdominal hypertension and abdominal compartment syndrome. Intensive care med. 2006; 92: 1722-32.

[25] Malbrain ML, Cliamello D, Pelosi P, Bihri D, Innes R, Ranieni UM, et al, incidence and prognosis of intra-abdominal hypertension in a mixed population of critically ill patients : A multiple center epidemiological study, Crit Care Med 2005; 33:315-22.

[26] Malbrain ML, Deeren D, De Potter TJ, Intra-abdominal hypertension in critically ill, it is time to pay attention curr opin crit care, 2005; 11 : 156-71.

[27] Malbrain ML, Minerva Anaesthesil. 2008; 74: 1-2. 


\section{Staged Abdominal Repair Surgery in Abdominal Compartment Syndrome- An Observational Study}

[28] Malbrain ML. Different techniques to measure intra-abdominal pressure (IAP) : time for a critical re-apprisal, Intensive care Med. $2004 ; 30: 357-71$

[29] Michard F, Teboul JL, Predicting fluid responsiveness in ICU patients. Chest, $2002: 121: 2000-8$.

[30] Planteteve M, Hellmann R, Pejot O, Thirion M, Bleichner G, Mente H. Abdominal compartment syndrome and intra-abdominal sepsis : two of the some kind? Acta clin Belg Suppl. 2007; 62 : 162-7.

[31] Rigin E, Kessel B, Ashkerazi I, Lieberman N, Alfici R, A new technique of direct intra-abdominal pressure measurement : A preliminary study. Am J Surg. 2006; 191: 235-7.

[32] Sabiston's textbook of surgery, $17^{\text {th }}$ and $18^{\text {th }}$ edition.

[33] Sanchez NC, Tenofsky PL, Dort JM, Shen LT, Halmer SP, Smith RS. What is normal intra-abdominal pressure ? Am Surg. 2001; 67:243-8.

[34] Schochtrup PA, Fackeldey V, Klinge U, Hoer J, Tillel A, Toenic et al, Temporary closure of abdominal wall (Laparostomy). Hernia 2002; 6: 155-62.

[35] Schwartz's Principle of Surgery, $9^{\text {th }}$ edition.

[36] Sieh KM, Chu KM, Wong J. Intra abdominal hypertension and abdominal compartment syndrome. Langeback's Arch Surg; 386 : 53-61.

[37] Sugrue M, Bauman A, Jones F, Biship G, Flabouris A, Parr M et al. Clinical examination is an accerate predictior of Intra-abdoin pressure. World J Surg. 2002; 26 : 1428-31.

[38] Surerman HJ, Effects of increased, intra-abdominal pressure in severe obesity. Surg Clin North Am. 2001; 81:1063-75.

[39] Synopsis of surgical anatomy, Lee, Mcgregor, $12^{\text {th }}$ edition.

[40] Van Hee R, Historical highlights in concept and treatment of abdominal compartment syndrome. Acta Clin Belg Suppl 2007; 62-915.

[41] Wittmann DM, Apramica C, Bengstein JM, Edmiston CE, Frantzides CT, Quebbeman EJ, et al. A burr like device to facililate temporary abdominal closure in planned laparostomy. Eur J Surg, 1993; 159:75-9. 